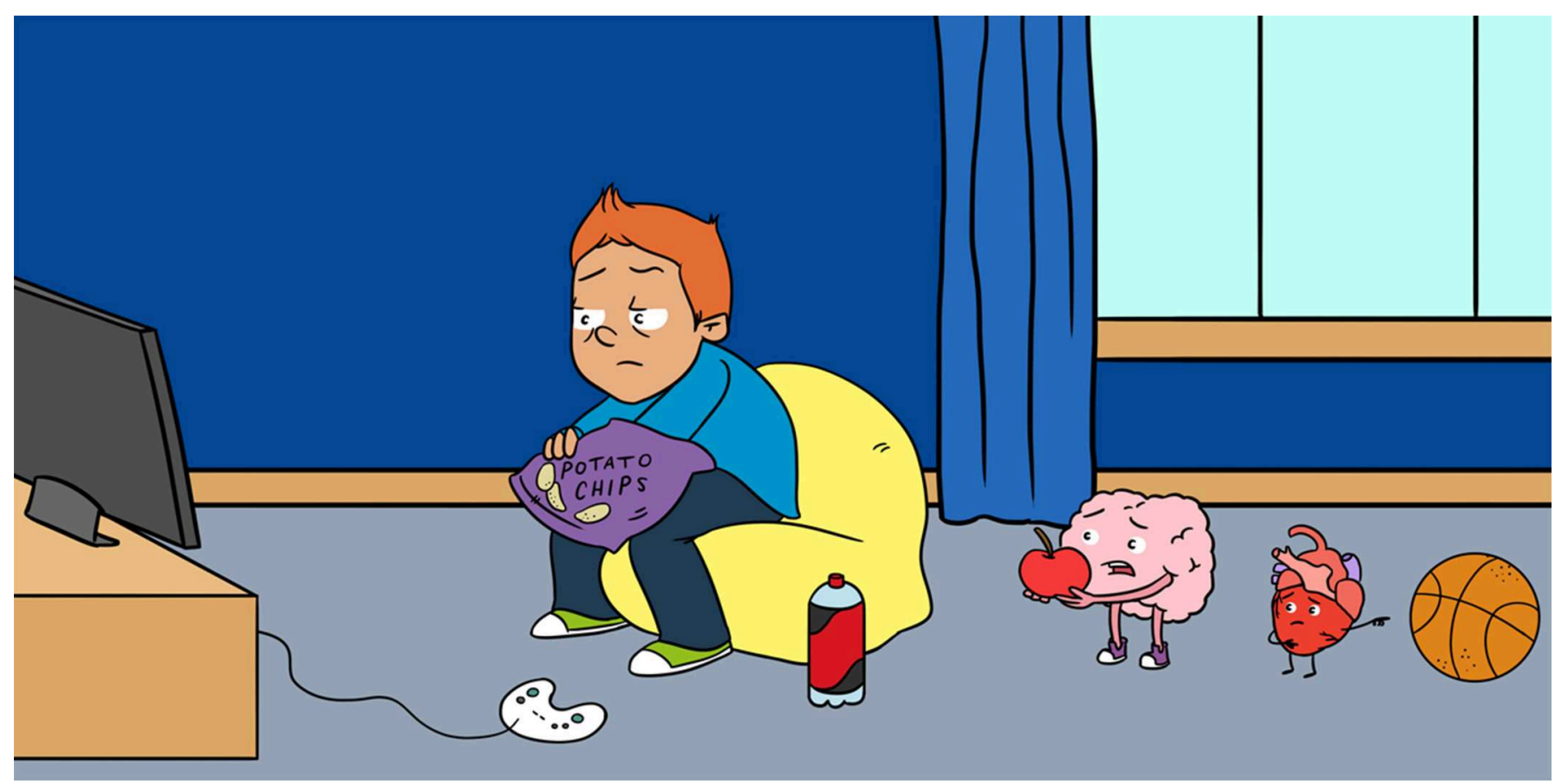

\title{
MIGHT LIFESTYLE CHOICES REDUCE THE RISK OF DEPRESSION?
}

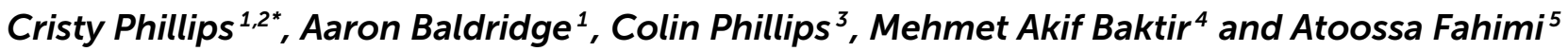 \\ ${ }^{1}$ Department of Physical Therapy, Arkansas State University, Jonesboro, AR, United States \\ ${ }^{2}$ University of Tennessee Health Science Center, Memphis, TN, United States \\ ${ }^{3}$ Department of Biology, Lyon College, Batesville, AR, United States \\ ${ }^{4}$ Department of Physiology, School of Medicine, Erciyes University, Kayseri, Turkey \\ ${ }^{5}$ Silverberry Genomics, San Francisco, CA, United States
}

YOUNG REVIEWER:

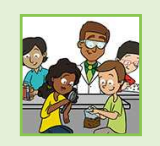

\section{EMILY}

AGE: 15

\section{DEPRESSION}

A mental illness that causes intense sadness and changes in the way a person thinks, feels, and behaves.
Depression is a common mental illness that affects millions of people worldwide. Depression is not sadness. The low mood in depression is more intense than the typical experience of sadness. It lasts over 2 weeks and interferes with daily activities. Too much stress can contribute to depression and other health problems. Stress does that by changing the balance of chemicals, hormones, and immune proteins. In this article, you will learn about new research on the connections between stress, inflammation, and depression. You will also learn how lifestyle choices can promote brain health, lower the bad effects of stress, and reduce the risk of depression.

Depression is a mental illness that impacts millions of people. It affects the way a person thinks, feels, and behaves. Depression is more intense than the experience of sadness. Important symptoms of depression include low mood, loss of pleasure, weight loss or gain, low energy, 


\section{STRESS}

A state where the body responds to mental, emotional, or physical threats.

INFLAMMATION

A state in the body in which the immune system responds to disturbances in the balance of body systems, injury, or infection. and feelings of hopelessness. These symptoms last over 2 weeks and interfere with a person's daily activities. Depression affects the depressed person, the person's family, and the community. In the United States, over 80 billion dollars a year is spent on depression. Most important, depression can be fatal, so it requires as much care as a serious physical illness.

We need to understand the causes of depression. This need has prompted decades of study. Research now shows that many factors contribute to depression. Of the known factors, stress is very important. Stress can cause depression over time [1]. Fortunately, lifestyle choices can reduce the ill effects of stress and depression. Let us consider factors that contribute to an increased risk for depression and decide if we can choose a path of health that reduces our risk of this illness.

\section{STRESS CAN CAUSE DEPRESSION}

Stress is usually a good thing, because it occurs when the brain perceives a threat. When that happens, the brain responds to the perceived threat by releasing stress hormones, such as cortisol. These hormones travel through the blood to the rest of the body, to help us respond to the threat [2]. For instance, under stress, heart rate increases, and our cells supply us with more energy.

After the threat ends, the stress response usually stops quickly. But not always. If the stress continues, then the stress response also continues. This disrupts the body's balance, because the body's stress shut-off mechanism stops working and the tissues become used to the stress hormones. The parts of the brain that control the stress response become damaged. The amygdala - the part of the brain that detects threats and makes us feel fear-grows in size and begins talking too much to the other brain regions. Negative brain talk then dominates. Sometimes, these chemical changes in the brain are related to inflammation caused by the stress.

\section{CONNECTING STRESS AND INFLAMMATION}

Inflammation is the immune system's first line of defense in dealing with threats. The immune system constantly monitors the brain and body for threats. The types of threats that the immune system is looking for include mental challenges, relationship challenges, injuries, irritations, diseases, or toxins. So usually, inflammation is another good thing. However, long-term stress can cause excessive inflammation. This happens because the continuing stress causes the immune system to produce pro-inflammatory proteins, which signal that there is a threat to the body, even when there is none. Trouble results if pro-inflammatory immune proteins stay active for 
NEUROTRANSMITTER

A chemical substance that conveys information from one neuron in the brain to another.

\section{NEUROGENESIS}

A process in certain parts of the brain where new neurons are formed to replace those that are injured. too long. Healthy cells, blood vessels, and tissues become damaged. The pro-inflammatory proteins also cause changes in the brain.

Evidence links pro-inflammatory immune proteins with depression. For one thing, depressed people have more pro-inflammatory proteins. Second, people who have been exposed to long-term stress often have both inflammation and depression. Third, people with inflammatory conditions often get depressed. Fourth, animal studies show that animals get depressed when given pro-inflammatory substances. They get better after being given anti-inflammatory medicines. All these pieces of evidence link inflammation to depression in certain people [3].

\section{A UNIQUE TYPE OF DEPRESSION RESULTS FROM STRESS AND INFLAMMATION}

Several studies support the idea that inflammation caused by stress creates a unique type of depression. Pro-inflammatory proteins cause an imbalance in chemicals in the brain (see Figure 1). These chemicals allow different kinds of "talk" to go on in the brain. Specialized chemicals, called neurotransmitters, can talk in the brain in different ways. Serotonin talks about eating, sleeping, learning, and feeling good. Dopamine talks about movement, reward, and motivation. Serotonin and dopamine talk together about well-being. Norepinephrine talks about threat and whether to fight or flee the threat. When the balance of these chemicals is disturbed, the message that results from their chatter shifts toward a negative bias. This negative bias can contribute to symptoms of depression.

Drugs for depression are called antidepressants. These drugs target neurotransmitters in an attempt to make their levels normal. The problem is that these drugs do not work for everyone. Many people who take antidepressants fail to get relief from their depression. For those who do benefit, the effects take weeks. The reason that antidepressants might not work well in all people may be connected to neurogenesis, which is the brain's process of making new neurons. Neurogenesis occurs in a part of the brain called the hippocampus. Some newly born neurons in the hippocampus start working to regulate stress, and these new neurons may help to decrease depression. However, people with stress, inflammation, and depression tend to have low levels of neurogenesis. As a result, damaged neurons are not replaced in the brain in an ongoing process. This may cause antidepressants to fail, because the brain requires both newly born neurons and restored levels of neurotransmitters to heal effectively [4]. 
Figure 1

Overview of the effects of stress on the brain and body. Stress affects the immune, nervous, and endocrine systems. Specifically, stress alters the release of pro-inflammatory proteins from cells in the immune system; in turn, pro-inflammatory proteins work on other systems.

Pro-inflammatory proteins alter neurotransmitter function in the brain and the release of stress hormones in the body. Also, stress directly alters the release of neurotransmitters in the brain. In the turn, neurotransmitter changes alter the function of immune proteins and the release of stress hormones. Finally, stress directly alters the release of stress hormones from glands in the endocrine system (or the adrenal glands which sit on the kidneys). In turn, the release of stress hormones then affects the function of neurotransmitters and immune system. Together, these direct and indirect changes in the brain and body cause symptoms of depression.

\section{LIFESTYLE FACTORS}

Modifiable choices that influence health and well-being.

\section{EXERCISE}

Activity that requires physical effort and is carried out to improve health.

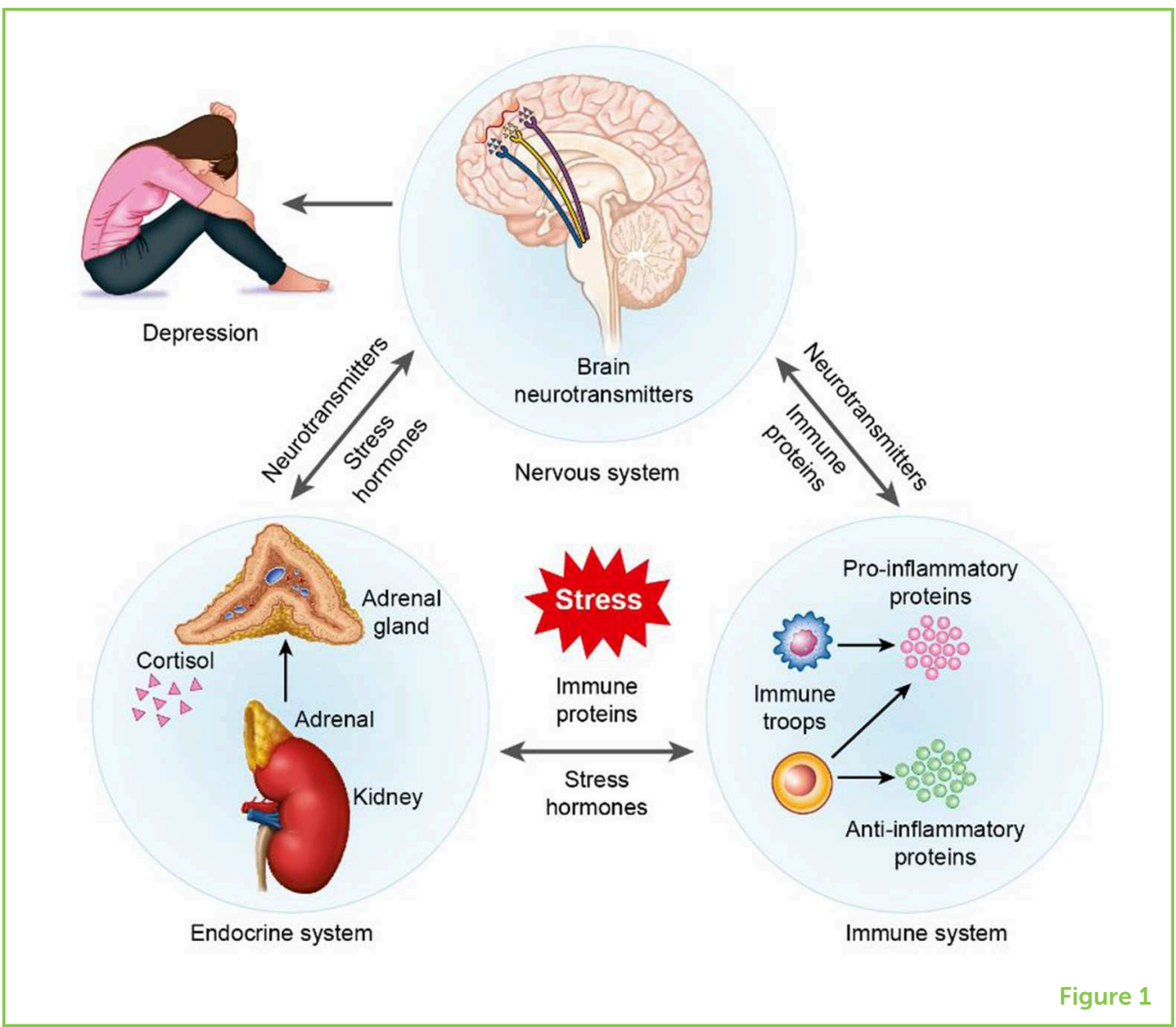

\section{REDUCING THE RISK FOR DEPRESSION THROUGH LIFESTYLE FACTORS}

Some people think that depression cannot be prevented. This is because many risk factors for depression are fixed, meaning they are genetic, environmental, and biological factors that are impossible or very difficult to change. Yet not all key factors are fixed. Many lifestyle factors can be modified [5].

Lifestyle factor choices, such as what we eat, how much sleep we get, and how much we exercise, can increase or decrease stress. These lifestyle factors can also have pro- or anti-inflammatory effects. So, depression might serve as a signal that we need to make better lifestyle choices. A balanced lifestyle that takes into account diet, exercise, and sleep reduces the bad effects of stress and inflammation on the body and the brain.

Eating correctly protects the brain. A healthy diet includes nutritious foods and limits calories, sugars, and saturated fats. According to the recommended guidelines, people ages 10-18 should consume $2,000-3,200$ calories daily. The exact number of calories that should be eaten depends on the person's sex and activity level. Yet, it is not just about calories. There is good evidence that some foods help the body and brain deal better with stress and inflammation and, in 
doing so, also reduce the risk of depression. For example, low-fat and low-sugar diets reduce inflammation and promote health. Also, a diet high in plant-based foods is important, because these foods contain anti-inflammatory compounds. This is an excellent reason to include plenty of fresh vegetables and fruits in our diets.

Exercise is also an important lifestyle factor choice, because it reduces the activity of the body's stress and inflammation systems. Exercise does this in part by reducing pro-inflammatory proteins and increasing anti-inflammatory proteins in the blood. Today, we can engage in many activities that are not very physical. These include watching TV, playing video games, and surfing the Internet. All these activities may be fun and valuable, but it is also very important to get daily physical exercise. Children and teens ages 6-17 should get 60 min of physical activity each day. Healthful and beneficial physical activities include playing baseball, soccer, and other team sports, as well as running, swimming, walking, hiking, and mowing the lawn. In fact, these activities include just about anything that gets us out of our chairs and moving. The great thing about exercise is that it makes both the body and the brain happy. That is why we need to make daily exercise a habit when we are young. We should also make regular exercise a lifelong goal. If we do that, we will enjoy health benefits throughout life. These benefits include reduced stress levels, reduced risk of excess inflammation, and reduced risk of becoming depressed.

Sleep is a third important lifestyle factor for brain and body health. Many people eat an appropriate diet and exercise regularly, but then they cancel the positive effects of those choices by sleeping only $4-5 \mathrm{~h}$ per night. Lack of sleep is a problem, because it causes the release of pro-inflammatory proteins and negatively changes hormone levels. These changes increase the risk of becoming depressed. Children and teens need plenty of sleep, because their bodies and brains are still growing. The recommended amount is $8-10 \mathrm{~h}$ of sleep each night. Without enough sleep, the brain does not work at peak efficiency. But, after adequate sleep, the brain is sharp and the body is ready for action.

\section{CONCLUSION}

Our healthy lifestyle choices can (1) build the brain's and body's protection against stress and inflammation, (2) lower the risk for depression, and (3) reduce the symptoms of depression in those who are already depressed. This knowledge suggests that we need to make choices that promote brain and body health. We also need to monitor ourselves to make sure we are consistently making healthy choices. When we make these good choices about diet, exercise, and sleep, we are better able to cope with illness when it strikes. We can also help those we love to improve their own health by serving as good examples. 


\section{REFERENCES}

1. Russo, S. J., Murrough, J. W., Han, M. H., Charney, D. S., and Nestler, E. J. 2012. Neurobiology of resilience. Nat. Neurosci. 15:1475-84. doi: 10.1038/nn.3234

2. Joels, M., and Baram, T. Z. 2009. The neuro-symphony of stress. Nat. Rev. Neurosci. 10:459-66. doi: 10.1038/nrn2632

3. Iwata, M., Ota, K. T., and Duman, R. S. 2013. The inflammasome: pathways linking psychological stress, depression, and systemic illnesses. Brain Behav. Immun. 31:105-14. doi: 10.1016/j.bbi.2012.12.008

4. Phillips, C., and Fahimi, A. 2018. Immune and neuroprotective effects of physical activity on the brain in eepression. Front. Neurosci. 12:498.

doi: 10.3389/fnins.2018.00498

5. Lopresti, A. L., Hood, S. D., and Drummond, P. D. 2013. A review of lifestyle factors that contribute to important pathways associated with major depression: diet, sleep and exercise. J. Affect. Disord. 148:12-27. doi: 10.1016/j.jad.2013.01.014

SUBMITTED: 28 November 2018; ACCEPTED: 20 November 2019; PUBLISHED ONLINE: 11 December 2019.

EDITED BY: Daniel F. Hermens, Sunshine Coast Mind and Neuroscience Thompson Institute, University of the Sunshine Coast, Australia

CITATION: Phillips C, Baldridge A, Phillips C, Baktir MA and Fahimi A (2019) Might Lifestyle Choices Reduce the Risk of Depression? Front. Young Minds 7:137. doi: 10.3389/frym.2019.00137

CONFLICT OF INTEREST: The authors declare that the research was conducted in the absence of any commercial or financial relationships that could be construed as a potential conflict of interest.

COPYRIGHT @ 2019 Phillips, Baldridge, Phillips, Baktir and Fahimi. This is an open-access article distributed under the terms of the Creative Commons Attribution License (CC BY). The use, distribution or reproduction in other forums is permitted, provided the original author(s) and the copyright owner(s) are credited and that the original publication in this journal is cited, in accordance with accepted academic practice. No use, distribution or reproduction is permitted which does not comply with these terms.

\section{YOUNG REVIEWER}

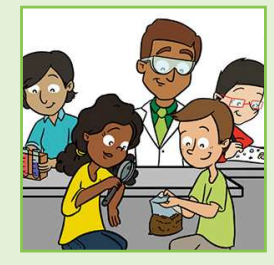

\section{EMILY, AGE: 15}

We are high-school students at Siena College. We have a variety of interests and enjoy studying sciences and the humanities. We were pleased to contribute to this interesting article. 

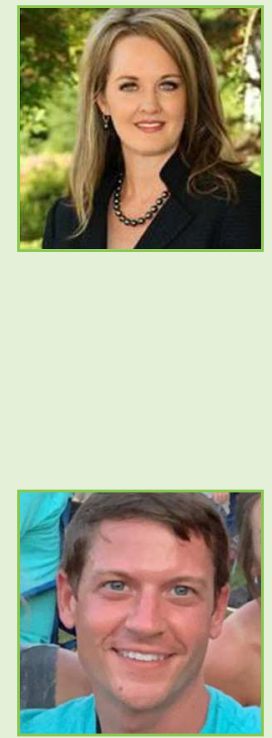

\section{AUTHORS}

\section{CRISTY PHILLIPS}

I am an Associate Professor at Arkansas State University, an Associated Faculty member with the University of Tennessee Health Sciences, and former CEO of a physical therapy company. As a translational neuroscientist, my research attempts to integrate the latest neurobiological research into rehab medicine to solve unmet clinical problems, including how to utilize lifestyle interventions and personalized medicine to treat mental illness and neurodegenerative disease. Therein I practice what I preach by paying attention to what I eat, how much I exercise, and making sure that I get enough sleep. ${ }^{*}$ cphillips@astate.edu

\section{AARON BALDRIDGE}

I graduated from Lyon College with majors in biology and psychology and a minor in French, and I am currently a third-year physical therapy student at Arkansas State University. My primary area of interest within physical therapy is geriatrics. I believe that we in physical therapy should be on the forefront of lifestyle modifications to improve health, particularly physical activity.
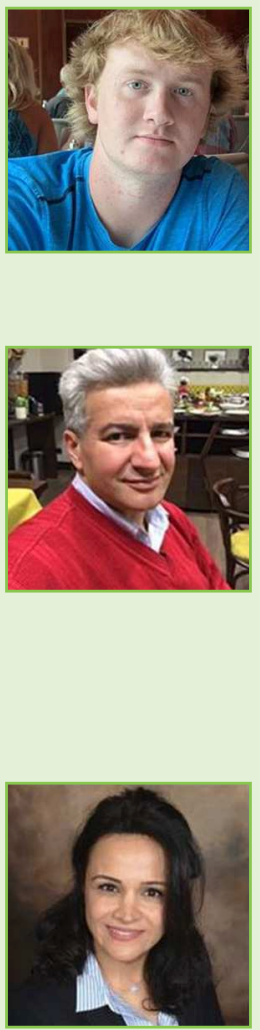

\section{COLIN PHILLIPS}

I am a second year college student working on a biology degree at Lyon College. I hope to go to medical school after I graduate. As a former football and baseball athlete, I know the importance of diet, fitness, and sleep in health and performance. I also know the importance of being mindful of lifestyle choices so that I can protect my brain and body as I age.

\section{MEHMET AKIF BAKTIR}

I am currently a lecturer in Erciyes University Faculty of Medicine, Department of Physiology. After graduating from Erciyes University Faculty of Medicine, I completed a specialization in medical physiology at the same university. Then, I worked as a doctor at a Bone Marrow Transplant Center for 2 years. Later, I worked for 2 years as a visiting researcher at Stanford University Medical School in the Department of Cardiovascular Medicine. Part of my current research interest is about how exercise can be used to protect the brain. I was born in 1973 in Turkey.

\section{ATOOSSA FAHIMI}

I am a physician-scientist working on Alzheimer's disease. I studied different aspects of neuroscience, such as memory, sleep, depression, stress, and addiction. Currently I am editing a clinical neurology handbook which will provide guidelines for clinicians. In my spare time, I exercise so as to improve my own memory and learning. I grew up in Iran, finished medical school in Europe, and completed a fellowship in neuroscience at Stanford Medical School. I believe we all can help humanity regardless to our ethnicity or background. 